Sanitary Authorities that the latter might include in their housing schemes dwellings required by the County Council for their officials, the County Council, of course, defraying the cost.

The Durham County Council has decided to establish a Central Housing Bureau to which Local Authorities in the county are asked to send the particulars and plans of their housing schemes, which will be tabulated and displayed, and open for inspection by Sanitary Authorities and their officers.

\title{
Dwellings for the Poor.
}

\section{By Charies S. Errington, F.R.I.B.A.}

$\mathrm{T}$ HOSE of us whose daily work lies in, or near, the centre of our large populations have opportunities of seeing how the poor live which are denied to others, and it must be evident to all such that the only method of dealing satisfactorily with large areas of slum property is entire removal and rebuilding on good substantial lines, care being taken that proper consideration is given to all sanitary and hygienic matters.

Having for many years been deeply interested in this subject, I have spent considerable time in inspecting and studying the methods adopted in rebuilding large areas of slum property by the London County Council, the Liverpool Corporation and others. I am also familiar with the schemes of Imany of the large Housing Trusts, which have done and are doing such excellent work in dealing with this most difficult problem.

Just at the moment it has become the fashion to taboo tenements or flats, chiefly because many of those in existence have not been conceived in the right spirit, or on the right lines, but this type, if properly conceived, with a proper regard for environment, amenity and convenience, is one which will appeal in the near future to housing reformers for all classes, where by necessity or desire they require to dwell near the centre of the area which offers them employment.

One reason why blocks of tenements have been the subject of so much condemnation is that too much has been attempted, and the cause of failure is the same as in other classes of dwellings, where the endeavour seems always to have been to see how many families could be squeezed on to a given space.

When we think that some of the blocks are of five, or even six stories in height, with spaces between the blocks sufficient for sunshine to enter the windows of the two stories only, some arranged back to back, with no pro- 
vision for through ventilation, wedged together in a way which may be ingenious, but is certainly not satisfactory, and with other defects which it is not necessary to go into but the chief of which is the provision of sanitary conveniences isolated from the dwellings, for use in common by several families, the condemnation is not surprising, and it is for an improved type that I ask your consideration.

I am not going to compare the advantages of semi-detached houses or houses in small blocks in the suburbs, for the bulk of our working classes, with the alternative of tenements or flats in or near the central area, but I am concerned in seeing that those whose labour or work necessitates their residing in proximity to their work should have dwellings which would be homes in the proper sense, in which they might have reasonable pride, in which they would have all the accommodation they require, and that selfcontained and not in common with their neighbours.

One of the first considerations in developing a slum area and in connection with the layout would be the setting apart of some proportion of the space hitherto given up to front and back streets and back yards, in order to provide suitable open spaces where the children could play in comparative safety, and where their parents might find recreation and enjoy fresh air in their leisure.

The area of land given up to streets and back yards in the past has been out of all proportion to the advantages gained, and I advocate the communal use of all the land remaining, after the self-contained homes and a sufficiency of land for convenient access to the same, have been provided for.

The question of aspect is one which is not likely to be forgotten in the future as it has so frequently been in the past, and no habitable room should be so conceived that it does not receive what sunshine there is, at some time of the day, the more the better, and it will be found that frontages facing east and west will give the best results in the most economical way.

The question whether the tenements or flats are on two stories or three stories will depend on various economic problems, but chiefly on the width of the land which can be left for open spaces between the blocks. Three stories should be the limit, and a very satisfactory combination would be two stories, with additional bedroom accommodation for the upper tenements within the slope of the roof, the ground floor thus being reserved for the smaller families. This matter of the bedroom accommodation requires most careful consideration, and it will not be met by providing everyone with three bedrooms, necessitating, in the case of small families, the taking in of lodgers, or in a combination of two or more families in one home, which things are not desirable.

I view with satisfaction that $8 \mathrm{ft}$. height of stories from floor to oeiling is 
now not only possible but is regarded as sufficient. There is nothing which will conduce more to a homely appearance and the effect of two-storied tenements of this height, with the additional bedroom accommodation for the upper tenements in the roof, might be made quite charming and homelike, providing that the floor area is kept on the large s!de.

The type of tenement dwellings for which I have the most admiration is that with open balconies, for access to the upper tenements, approached by a staircase with one open end. By this means the entrance doors all communicate direct with the open air, and ensure through ventilation in the dwellings when the door is opened in combination with the open windows on the opposite frontage.

It is desirable that the living room and bedroom windows should not be made to face on to the balcony, and there appears to be no great difficulty in arranging this.

Six tenements on each floor are probably as many as should be attempted in blocks of the type under consideration, and these can be approached from a central staircase.

It is essential that the living room should be of good size and proportions, but I consider that the area might increase with the larger number of bedrooms provided. Seeing that the living room may have to suffice for sleeping accommodation, under certain conditions, the floor area should not be less than $180 \mathrm{ft}$.

It is very much in evidence that the dwellings of the future will all be provided with adequate scullery and bathroom accommodation, and another of the defects which will, I hope, disappear, is the inadequate provision for food storage and coal storage.

The floors should all be of fireproof construction, and anything which will allow of these being less conductive of sound than they usually are will be very much appreciated. Patent jointless composition floors laid on concrete have been in general use for some time in living rooms and bedrooms, and some have stood the test very well. Others, however, have failed, and I am inclined to think that good, thick linoleum of the best quality fixed with a proper solution to the cement is as good a finish as any. The margins, however, should be of cement, rounded off at the junction with the wall, and the cement should be countersunk for the linoleum.

This matter of the linoleum on cement has been one of the war measures, and it may be that it has come to stay.

The class who will occupy this type of dwelling will, for many reasons, appreciate hanging cupboards in the bedrooms, dressers or presses in the living rooms, and such other appliances as will assist them to keep their places 
tidy, the provision of which is all the more important seeing that those who are to inhabit the dwellings have not the means to procure them otherwise.

I hope that no one will ever again think of suggesting that the sanitary conveniences may be shared in common by a number of families. I see no reason why each dwelling should not have this accommodation provided indoors, care being taken that it is capable of proper ventilation.

With reference to the hot water supply, there are combination ranges to be obtained for living rooms which give not only a good fire and oven for cooking and bread-baking, but a hot water service to the bath and to the sink and washing copper in the scullery. It is well worth while to so adapt the plan and arrangement of the fittings that this important provision may be effectual in its results.

This subject is now going to receive the attention it deserves. In the near future we shall no doubt see new suburbs growing up, conceived on lines which will ensure a healthy environment, and if the same skill and attention is devoted to rebuilding the slums we may have good cause to be thankful, for the results will manifest themselves in all directions.

\section{Housing Schemes and the Adaption of Central Heating and Hot Water Supply.}

By Prof. J. Radcliffe, M.Sc.Tech. (Fellow).

(ABSTRACT.)

T is essential that all buildings occupied as human habitations should be designed so that health conditions may be combined with comfort, and receive first consideration. In northern districts sharp variations of temperature occur. Individual susceptibilities to variations of temperature and moisture differ widely. In practice the problems of heating are very closely associated with ventilation. Long established custom and prejudice have caused the general use of open fire grates for heating almost all the houses in this country. The waste of fuel by the use of this type of grate is enormous, and the pollution of the atmosphere from this source is very great. Many people believe that the open kitchen range is necessary when a supply of hot water for bath and other purposes is required; that is an erroneous impression. Efficient means are available for providing and distributing heat to each dwelling from central positions, and also for the efficient distribution of hot water to each house.' To provide for variation in the requirements of each house and to supplement the general scheme for heating, a modern fire grate in each house should be available whenever required for special 